\title{
Affinity of Compounds in Hemigraphis Alternata (Burm.F.) T. Ander Leaves to Cyclooxygenase 1 (COX-1): In Silico Approach
}

\author{
Yeni Yeni ${ }^{1, *}$ Rizky Arcinthya Rachmania ${ }^{2}$ Mochamad Dicky Yanuar M R
}

${ }^{1,2,3}$ Department of Pharmacy, Universitas Muhammadiyah Prof. DR. HAMKA, Jakarta, Indonesia

*Corresponding author. Email: yeni@uhamka.ac.id

\begin{abstract}
Inflammation is an important biological process for eradicating pathogens and maintaining tissue homeostasis. Cyclooxygenase $1(\mathrm{COX}-1)$ is one of the pharmacological targets for anti-inflammatory drugs. The purposes of this study was to predict the affinity of 23 compounds contained in Hemigraphis alternata leaves in inhibiting COX-1. The compounds of Hemigraphis alternata leaves were screened for its affinity towards COX-1 using docking software, DOCK 6.9, with aspirin as the reference. Based on the Grid score, the greatest binding affinity is referred to 3,7,11,15-tetramethyl-2-hexadecen-1-ol. It is better than affinity of aspirin to COX-1. The study showed that Hemigraphis alternata leaves contain potential active components that could be developed as COX-1-inhibitor.
\end{abstract}

Keywords: Hemigraphis alternata, Cyclooxygenase 1, In silico.

\section{INTRODUCTION}

Inflammation is a pathophysiological response to infection or tissue damage [1]. The biological process is important for pathogen eradication and maintenance of tissue homeostasis [2], [3]. Inflammation is a reflection of cell damage caused by infection, physical injury or tissue response to antibody rejection [4]. Clinical symptoms of inflammation are characterized by rubor (redness), calor (heat), tumor (swelling), dolor (pain) and functio laesa (loss of function) [5].

Hemigraphis alternata has a long history as ethnomedicine for wound healing and has been recorded in ancient Indian medicinal texts since 3000 BC [6]. This plant contains flavonoids which are predicted to provide antiinflammatory effects [7], [8]. There are 23 secondary metabolites that have been isolated from the plant [6].

Non-steroidal anti-inflammatory drugs (NSAIDs) are the most commonly anti-inflammatory drugs used in the worldwide. They act via cyclooxygenase isozyme (COX) inhibition and are a key component of pharmacological management of acute and chronic pain [9]. COX-1 is constitutively expressed in most tissues (eg, platelets, lung, prostate, brain, gastrointestinal tract, kidney, liver and spleen), whereas COX-1-derived prostanoids are involved in homeostatic function [10]. COX-2 is less widely expressed, constitutively expressed in several tissues and organs such as brain, kidneys and reproductive tract [11].

In silico study is individual computer simulations for development or evaluation of drugs [12]. In silico methods can be used to predict the drugs affect in biological systems which improve the clinical use, avoid the side effects and guide to the better treatment selection and development. This study provides additional benefits for generating hypotheses about the biological mechanism of drugs or disease in new drug candidates discovery [13].

Molecular docking is the activity of small molecules on the binding side of the protein target [14], [15]. The result of molecular docking is the energy required by the ligands to bind to proteins. The low bond energy indicates that the ligand is easy to bind to the target protein [16].

The aim of this study was to predict the anti-inflammatory compounds in the leaves of Hemigraphis alternata which have a greater affinity for COX-1 than the comparator drug, aspirin through in silico study. Therfore, new drug candidates can be obtained for anti-inflammatory.

\section{MATERIALS AND METHODS}

\subsection{Tools}

The hardwares used in this study were a set of laptop with specifications processor AMD-A4-9125 RADEON R3, 4 COMPUTE CORES $2 \mathrm{C}+2 \mathrm{G}$ (2CPUs) $\sim 2.3 \mathrm{GHz}$ with operating system windows 10 Home 64-bit and operating system Linux Ubuntu 16.04 LTS 64-bit and supercomputer processor AMD Ryzen 7 3700X, GPU Nvidia GetForce with operating system ubuntu 20.04. The softwares used were Protein Data Bank (http://www.rcsb.org/pdb), Chimera version 1.13, DOCK version 6.9, Discovery Studio Visualizer version 17.2.0.16349 and Pub-Chem (http://PubChem.ncbi.nlm.nih.gov). 


\subsection{Materials}

The three-dimensional (3D) structure of COX-1 receptor (PDB code 1eqg) was downloaded from Protein Data Bank. The 3D structure of 23 ligands and aspirin were downloaded from PubChem.

\subsection{Methods}

Docking study were conducted using DOCK with flexible docking method. The first step in docking using DOCK program is to create a receptor surface using a Chimera, make and select the sphere. The purpose of making spheres is to make clusters on the receptor so that the coordinates of the ligand-receptor bonds are known. Next is making boxes and grids, then do molecular docking [16].

Redocking receptor COX-1 with its native ligand, ibuprofen was carried out first to validate the method to obtain Root Mean Square Deviation (RMSD) $\leq 2 \AA$ [17]. This validation was carried out to know that the molecular docking system could obtain results which corresponds to the crystallographic ligand conformation [16].

Molecular docking was performed on ligands and the comparator drug, aspirin. The result is a grid score. The ligand with the smallest grid score is the best ligand because the energy used to bind to the receptors is getting smaller. After that, the docking results were visualized by Discovery Studio Visualizer to determine the bonds formed between the best ligand and the COX-1 receptor.

\section{RESULTS AND DISCUSSION}

The technique used for 3D virtual screening in this study is the molecular docking method. The molecular docking method uses a search strategy with a scoring function [18].

The docking method used in DOCK 6.9 with the molecular shape algorithm [19] in this study is flexible docking or it can also be called soft docking, where the backbone of the receptors and ligands is in a mobile state. There are 3 docking methods, rigid body docking, flexible ligand docking and flexible docking [20].

The validation method was performed before starting the docking study with redocking the native ligand, ibuprofen against COX-1 to determine the reliability of the docking protocol. RMSD of Redocking COX-1 with its native ligand, ibuprofen is $1.6 \AA$. The result of redocking yields RMSD $<2$ $\AA$, meaning that this method can be used for virtually any compound screening [21].

The result of molecular docking using DOCK 6.9 is a grid score which is the sum of Van der Waals energy and electrostatic energy. The more negative grid score indicates a better bond between the ligand and the receptor [16].

The affinity of the compounds contained in the leaves of Hemigraphis alternata for anti-inflammation was known from the docking results against COX-1 (Table 1). The docking results showed that 3,7,11,15-Tetramethyl-2hexadecen-1-ol had the greatest affinity among the 23 compounds with a grid score of $-33.22 \mathrm{kcal} / \mathrm{mol}$. This shows that the affinity is higher than aspirin as a comparator drug which requires more energy to interact with COX-1, -14.47 $\mathrm{kcal} / \mathrm{mol}$.

In the molecular docking result of $3,7,11,15$ Tetramethyl-2-hexadecen-1-ol and COX-1 complex, there are 3 hydrogen bonds and 5 hydrophobic bonds (Figure 1). The hydrogen bonds formed in the complex are between $\mathrm{NH} 2$ arginine 459 receptor with O1 ligands (distance $3.36 \AA$ ), H40 ligands with $\mathrm{O}$ arginine 456 receptor (distance $2.83 \AA$ ) and H39 ligands with $\mathrm{O}$ arginine 456 receptor (distance $2.56 \AA$ ). The hydrophobic bonds formed in the complex are between alkyl proline 162 receptor with alkyl ligand (distance $5.42 \AA$ ), C12 ligand with alkyl proline 162 receptor (distance $4.22 \AA$ ), C13 ligand with alkyl valine 33 receptor (distance $4.83 \AA$ ), C18 ligand with alkyl proline 162 receptor (distance $5.12 \AA$ ) and C18 ligand with alkyl arginine 456 receptor (distance $4.62 \AA$ ). This compound was selected as a candidate for a new anti-inflammatory drug and is expected to be tested further for its activity against COX-1.

3,7,11,15-Tetramethyl-2-hexadecen-1-ol known as phytol (PYT) is an acyclic diterpene alcohol compound and a constituent of chlorophyll. 3,7,11,15-Tetramethyl-2hexadecen-1-ol is a phytanic acid (PA) compound which cause various biological effects. There are some evidences suggesting that PA may play an important role in the development of pathophysiological conditions. The studies that have been conducted have shown that 3,7,11,15Tetramethyl-2-hexadecen-1-ol has anxiolytic, metabolicmodulating, cytotoxic, antioxidant, autophagy- and apoptosis-inducing, antinociceptive, anti-inflammatory, immune-modulating, and antimicrobial effects [22].

\section{CONCLUSION}

The compound in Hemigraphis alternata leaves that has the greatest affinity for inhibiting COX-1 is 3,7,11,15Tetramethyl-2-hexadecen-1-ol. It has a greater affinity than aspirin as a comparator drug. This shows that the leaves of Hemigraphis alternata contain potential active components that can be developed as anti-inflammatory drugs. 


\section{FIGURES AND TABLES}

Table 1. Molecular docking result of the compounds to COX-1 using DOCK 6.9

\begin{tabular}{|c|c|c|c|c|c|}
\hline No & Compound & $\begin{array}{l}\text { Grid Score } \\
\text { (kcal/mol) }\end{array}$ & No & Compound & $\begin{array}{l}\text { Grid Score } \\
\text { (kcal/mol) }\end{array}$ \\
\hline 1 & Aspirin (comparator drug) & -14.47 & 13 & Z-2-Dodecenol & -23.18 \\
\hline 2 & 15-Chloro-4-pentadecyne & -25.87 & 14 & 15-Chloro-4-pentadecyne & -24.55 \\
\hline 3 & 4-(2-Methoxyphenyl)piperidine & -14.45 & 15 & 2-Methylenecholestan-3-ol & -28.16 \\
\hline 4 & Cyclobutanol & -9.84 & 16 & L- Alanine & -13.84 \\
\hline 5 & 1-Hexadecyne & -21.20 & 17 & levodopa & -22.53 \\
\hline 6 & 2-Propylmanonic acid & -19.90 & 18 & Glycylsarcosine & -20.07 \\
\hline 7 & n-Hexadecanoic acid & -29.89 & 19 & 5-Hydroxymethylfurfural & -13.71 \\
\hline 8 & 2-Hexylacrylonitrile & -15.85 & 20 & 10-Undecyn-1-ol & -20.09 \\
\hline 9 & $\begin{array}{l}\text { 3,7,11-Trimethyl-1,6,10- } \\
\text { dodecatrien-3-ol }\end{array}$ & -20.66 & 21 & $\begin{array}{l}\text { 2,5-Dimethyl-2,3-dihydro-5H-1,4- } \\
\text { dioxepine }\end{array}$ & $-12, .97$ \\
\hline 10 & $\begin{array}{l}\text { 8a-Methylhexahydro-1,8(2H,5H)- } \\
\text { naphthalenedione }\end{array}$ & -11.03 & 22 & 4-Nitro-5-hydroxy-1,2-dimethylindole & -16.82 \\
\hline 11 & $\begin{array}{l}\text { Acrylonitrile } \beta-[3-(2,2 \\
\text { dimethylcyclopropyl)-2,2- } \\
\text { dimethylcyclopropyl }\end{array}$ & -16.37 & 23 & $\begin{array}{l}\text { 9,9-Dimethoxybicyclo[3.3.1]nona-2,4- } \\
\text { dione }\end{array}$ & -14.49 \\
\hline 12 & $\begin{array}{l}3,7,11,15 \text {-Tetramethyl-2- } \\
\text { hexadecen-1-ol }\end{array}$ & -33.22 & 24 & $\begin{array}{l}\text { 2,7-Dioxa-tricyclo[4.4.0.0(3,8)]deca- } \\
\text { 4,9 diene }\end{array}$ & -9.31 \\
\hline
\end{tabular}

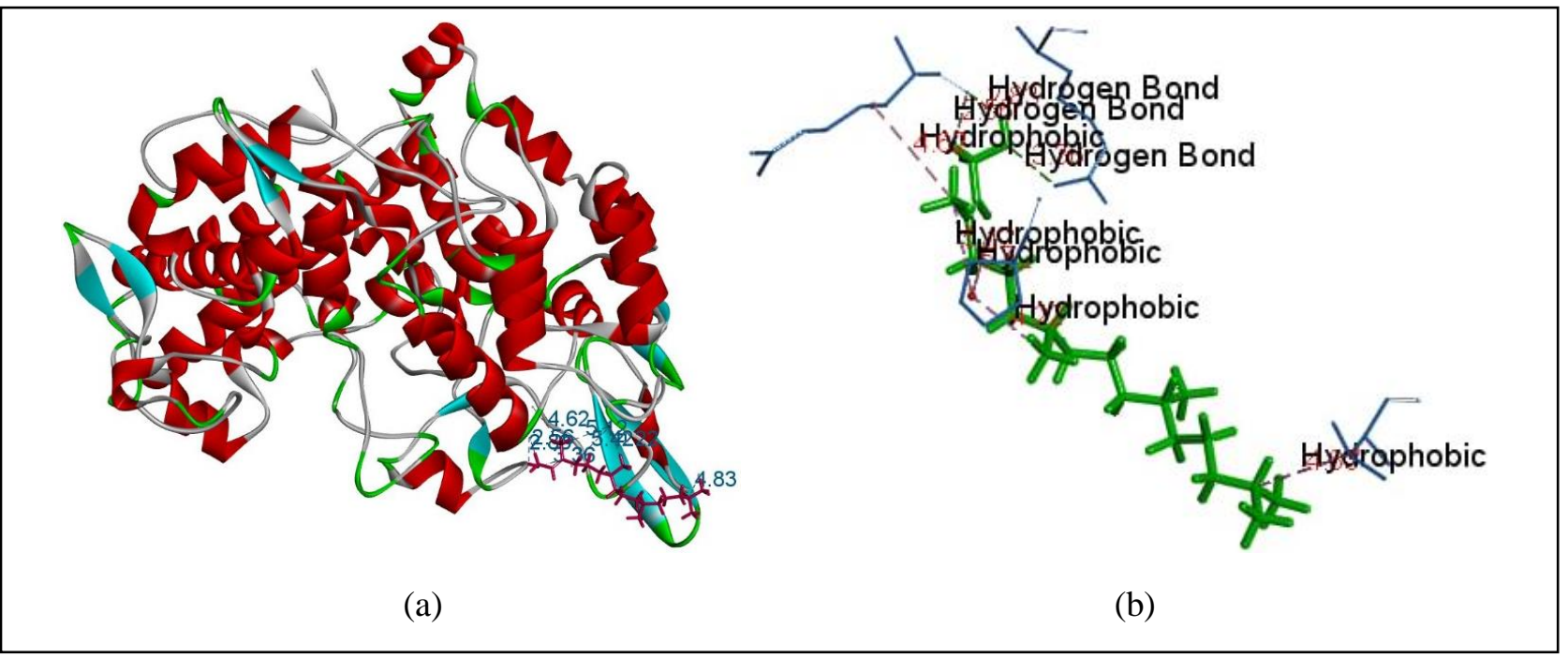

Figure 1 Visualization of docking result 3,7,11,15-Tetramethyl-2-hexadecen-1-ol to COX-1 using Discovery Studio Visualizer 17.2.0.16349 (a) 3D (b) 2D.

\section{AUTHORS' CONTRIBUTIONS}

Yeni Yeni; Conceptualization, data curation, writingoriginal draft preparation, writing-review and editing, supervision, project administration, funding acquisition. Rizky Arcinthya Rachmania; methodology, software and validation. Mochamad Dicky Yanuar M R; formal analysis, investigation, resources and visualization

\section{ACKNOWLEDGMENTS}

The authors acknowledg for the support received from . Institute for Research and Development, Universitas Muhammadiyah Prof. DR. HAMKA.

\section{REFERENCES}

[1] B. Knoops, V. Argyropoulou, S. Becker, L. Ferté, O. Kuznetsova, Multiple roles of peroxiredoxins in inflammation, Molecules and Cells, vol. 39, no. 1, 2016, pp. 60-64. DOI: 10.14348/molcells.2016.2341.

[2] F. Loi, L. A. Córdova, J. Pajarinen, T. hua Lin, Z. Yao, S. B. Goodman, Inflammation, fracture and bone repair, Bone. 2016. DOI: 10.1016/j.bone.2016.02.020.

[3] M. H. Praja, R. Z. Oktarlina, Uji Efektivitas daun petai cina (Laucaena glauca) sebagai antiinflamasi dalam pengobatan luka bengkak, Jurnal Majority, vol. 6, no. 1, 2017, pp. 60-63. 
[4] B. E. Leonard, Inflammation and depression: A causal or coincidental link to the pathophysiology?, Acta Neuropsychiatrica, 2018. DOI: 10.1017/neu.2016.69.

[5] N. Efron, Contact lens wear is intrinsically inflammatory, Clinical and Experimental Optometry, 2017. DOI: 10.1111/cxo.12487.

[6] W. K. A. K. Ming, Bioassay-Guided Purification and Identification of Chemical Constituents from Hemigraphis alternata, 2019.

[7] S. Adangampurath, S. Sudhakaran, Anti-inflammatory potential of flavonoids from Hemigraphis colorata, Int. J. Life Sci., 2018.

[8] A. Kashyap, N. P. Reddy, R. Karnati, Chaitanya R.K., Ethyl acetate extract of Hemigraphis colorata leaves shows anti-inflammatory and wound healing properties and inhibits 5-lipoxygenase and cyclooxygenase-1 and 2 enzymes, J. Med. Plants Res., 2013, DOI: 10.5897/JMPR2013.5184.

[9] K. Brune and P. Patrignani, "New insights into the use of currently available non-steroidal anti-inflammatory drugs," Journal of Pain Research. 2015, doi: 10.2147/JPR.S75160.

[10] A. Pannunzio, M. Coluccia, Cyclooxygenase-1 (COX-1) and COX-1 inhibitors in cancer: A review of oncology and medicinal chemistry literature, Pharmaceuticals, 2018. DOI: 10.3390/ph11040101.

[11]A. Zarghi, S. Arfaei, Selective COX-2 inhibitors: A review of their structure-activity relationships, Iranian Journal of Pharmaceutical Research, 2011. DOI: 10.22037/ijpr.2011.1047.

[12] M. Viceconti, A. Henney, E. Morley-Fletcher, In silico clinical trials: how computer simulation will transform the biomedical industry, Int. J. Clin. Trials, 2016. DOI: 10.18203/2349-3259.ijct20161408.

[13] R. A. Hodos, B. A. Kidd, K. Shameer, B. P. Readhead, J. T. Dudley, In silico methods for drug repurposing and pharmacology, Wiley Interdiscip. Rev. Syst. Biol. Med., 2016. DOI: 10.1002/wsbm.1337.

[14] N. S. Pagadala, K. Syed, J. Tuszynski, Software for molecular docking: a review, Biophysical Reviews. 2017. DOI: $10.1007 / \mathrm{s} 12551-016-0247-1$.

[15]E. Yuriev, J. Holien, P. A. Ramsland, Improvements, trends, and new ideas in molecular docking: 2012-2013 in review, Journal of Molecular Recognition, 2015. DOI: $10.1002 / \mathrm{jmr} .2471$.

[16] W. Atmajani, A. B. Kurniawan, R. Hapsari, B. Santoso, Kajian in Silico Agonis Ppar Gamma-Receptor Protein (5Y2O ) Sebagai Antihiperglikemia Menggunakan Dock6, 2019, pp. 193-200.

[17] A. Manna, M. D. Laksitorini, D. Hudiyanti, P. Siahaan, Molecular Docking of Interaction between E-Cadherin Protein and Conformational Structure of Cyclic Peptide ADTC3 (Ac-CADTPC-NH2) Simulated on $20 \mathrm{~ns}, J$. Kim. Sains dan Apl., 2017. DOI: 10.14710/jksa.20.1.30-
36.

[18]K. Hengphasatporn et al., Multiple virtual screening strategies for the discovery of novel compounds active against dengue virus: A hit identification study, Sci. Pharm., 2020. DOI: 10.3390/scipharm88010002.

[19] M. S. Murgueitio, M. Bermudez, J. Mortier, G. Wolber, In silico virtual screening approaches for anti-viral drug discovery, Drug Discovery Today: Technologies, 2012. DOI: 10.1016/j.ddtec.2012.07.009.

[20] X.-Y. Meng, H.-X. Zhang, M. Mezei, M. Cui, Molecular Docking: A Powerful Approach for Structure-Based Drug Discovery, Curr. Comput. Aided-Drug Des., 2011. DOI: $10.2174 / 157340911795677602$.

[21] A. Musoev, S. Numonov, Z. You, H. Gao, Discovery of novel DPP-IV inhibitors as potential candidates for the treatment of type 2 diabetes mellitus predicted by 3D QSAR pharmacophore models, molecular docking and de novo evolution, Molecules, 2019. DOI: 10.3390/molecules24162870.

[22] M. T. Islam et al., Phytol: A review of biomedical activities, Food Chem. Toxicol., 2018. DOI: 10.1016/j.fct.2018.08.032. 